

\section{Editor in Chief}

Enzo Boschi

\section{Executive Editor}

Calvino Gasparini

\section{Associate Editors}

Massimo Cocco, Massimiliano Stucchi, Gianluca Valensise,

Alessandro Amato, Paolo Baldi, Maurizio Bonafede, Rodolfo Console,

Michele Dragoni, Domenico Giardini, Carlo Giunchi, Stefano Gresta, Antonio Meloni, Andrea Morelli, Antonio Navarra, Antonio Rovelli, Jean Virieux, Bruno Zolesi

\section{Editorial Office}

Anna Grazia Chiodetti

Francesco Caprara

Istituto Nazionale di Geofisica e Vulcanologia

Via Donato Creti, 12

40128 Bologna - Italy

Tel. (39) 0514151417

Fax (39) 0514151499

E-mail: annals@ingv.it

\section{Editorial Production}

Editrice Compositori

Via Stalingrado, 97/2

40128 Bologna - Italy

Tel. (39) 0513540111

Fax (39) 051327877

E-mail: info@annalsofgeophysics.net

http://www.compositori.it

On the cover: Migrated and stacked GPR section Alb 4.8. Yellow boxes indicate anomalies due to wall response while blue box indicates a flat high-energy reflection probably due to a buried floor. The white box indicates a room filled up with backfill.

http://www.annalsofgeophysics.net

Annals of Geophysics is indexed in: Science Citation Index ${ }^{\circledR}$-Expanded (also known as SciSearch ${ }^{\circledR}$ ), ISI Alerting Services, INSPEC, GeoRef database. 


\title{
MIRTO: a prototype for real-time ionospheric imaging over the Mediterranean area
}

\author{
Lucilla Alfonsi $\left({ }^{1}\right)$, Cathryn N. Mitchell $\left({ }^{2}\right)$, Vincenzo Romano $\left({ }^{1}\right)$ and Paolo Spalla $\left(^{3}\right)$ \\ (') Istituto Nazionale di Geofisica e Vulcanologia, Roma, Italy \\ (2) Department of Electronic and Electrical Engineering, University of Bath, U.K. \\ ${ }^{(3)}$ Istituto di Fisica Applicata «Nello Carrara» (IFAC), CNR, Sesto Fiorentino (FI), Italy
}

\begin{abstract}
MIRTO (Mediterranean Ionosphere with Real-time TOmography) is a collaborative project between Istituto Nazionale di Geofisica (INGV) of Rome, the University of Bath (U.K.) and the Istituto Fisica Applicata «Nello Carrara»-Consiglio Nazionale delle Ricerche (IFAC-CNR) of Florence. The goal of the project is the development of a prototype for real-time imaging of the ionosphere over the Italian region with extension to the Mediterranean Sea. MIRTO uses an original imaging technique developed at the University of Bath and upgraded for real-time use in cooperation with IFAC. The prototype makes use of the data acquired by the real-time ionospheric and geodetic instrumentation operated by INGV. Such measurements drive the imaging algorithm to produce the image of electron density as well as maps and movies of the Total Electron Content (TEC) over the considered area.
\end{abstract}

Key words ionosphere - GPS - real-time imaging - TEC - tomography

\section{Introduction}

Tomography is a mathematical technique to reconstruct two-dimensional images and it is best known for the reconstruction of the human body from $X$-ray measurements (Hounsfield, 1972) in the Computer-Aided Tomography (CAT). In 1988 Austen and co-authors (Alfonsi et al., 1988) proposed imaging the Earth's ionosphere with tomography to determine the distribution of free electron concentration from satellite-to-ground radio signals.

Mailing address: Dr. Lucilla Alfonsi, Istituto Nazionale di Geofisica e Vulcanologia, Via di Vigna Murata 605, 00143 Roma (Italy); e-mail: lucilla.alfonsi@ingv.it
Ionospheric tomography is well established but from an application viewpoint has two critical drawbacks. First, tomographic images are only two dimensional (latitude versus altitude slices), whereas full three-dimensional images are usually needed. Second, conventional ionospheric tomography used data from Low-EarthOrbit (LEO) satellites that are not continuously in view. This meant that images can only be produced every few hours, at irregular intervals when a LEO satellite passes over the region of interest. This is a problem because the ionosphere can undergo significant changes on timescales of minutes, far shorter than the interval of time between consecutive tomographic images.

Since the availability of GPS satellites starting from early nineties, phase delay and pseudo-range measurements from a relevant numbers of ground stations have become available for research. These measurements furnish TEC evaluation along the huge amount of ray-path 


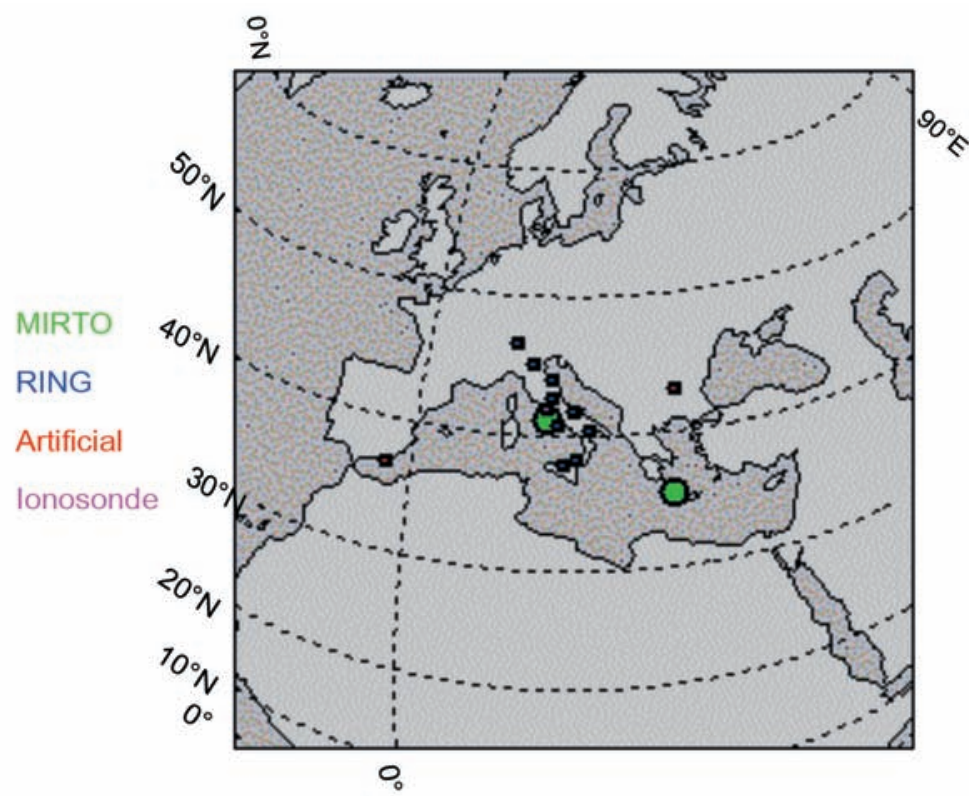

Fig. 1. Stations included in the MIRTO system.

Table I. Location and type of instrumentations of the MIRTO sites.

\begin{tabular}{ccccc}
\hline \hline Site & Station Code & Latitude & Longitude & Station \\
\hline Stuetta & STUE & $46^{\circ} 28^{\prime} 19.9^{\prime \prime} \mathrm{N}$ & $9^{\circ} 20^{\prime} 50.3^{\prime \prime} \mathrm{E}$ & GPS \\
San Benedetto Po & SBPO & $45^{\circ} 03^{\prime} 03.6^{\prime \prime} \mathrm{N}$ & $10^{\circ} 55^{\prime} 11.2^{\prime \prime} \mathrm{E}$ & GPS \\
Milazzo & MILA & $38^{\circ} 16^{\prime} 14.1^{\prime \prime} \mathrm{N}$ & $15^{\circ} 13^{\prime} 50.6^{\prime \prime} \mathrm{E}$ & GPS \\
Craco & CRAC & $40^{\circ} 22^{\prime} 53.0^{\prime \prime} \mathrm{N}$ & $16^{\circ} 26^{\prime} 06.6^{\prime \prime} \mathrm{E}$ & GPS \\
Ventotene & VENT & $40^{\circ} 47^{\prime} 40.9^{\prime \prime} \mathrm{N}$ & $13^{\circ} 25^{\prime} 17.8^{\prime \prime} \mathrm{E}$ & GPS \\
Leonessa & LNSS & $42^{\circ} 36^{\prime} 0.3^{\prime \prime} \mathrm{N}$ & $13^{\circ} 02^{\prime} 24.9^{\prime \prime} \mathrm{E}$ & GPS \\
Pesaro & PESA & $43^{\circ} 56^{\prime} 27.7^{\prime \prime} \mathrm{N}$ & $12^{\circ} 50^{\prime} 25.8^{\prime \prime} \mathrm{E}$ & GPS \\
Gibilmanna & GBLM & $37^{\circ} 59^{\prime} 25.2^{\prime \prime} \mathrm{N}$ & $14^{\circ} 01^{\prime} 34.1^{\prime \prime} \mathrm{E}$ & GPS \\
S. Elia a Pianisi & CIGN & $41^{\circ} 39^{\prime} 15.1^{\prime \prime} \mathrm{N}$ & $14^{\circ} 54^{\prime} 17.3^{\prime \prime} \mathrm{E}$ & GPS \\
Chania & Chania & $35^{\circ} 31^{\prime} 8.0^{\prime \prime} \mathrm{N}$ & $24^{\circ} 02^{\prime} 32.6^{\prime \prime} \mathrm{E}$ & GISTM \\
Montelibretti & Montelibretti & $41^{\circ} 06^{\prime} 0.0 \mathrm{~N}$ & $12^{\circ} 36^{\prime} 0.0^{\prime \prime} \mathrm{E}$ & GISTM \\
Cartagena & Cartagena & $36^{\circ} 42^{\prime} 00^{\prime \prime} \mathrm{N}$ & $02^{\circ} 30^{\prime} 00^{\prime \prime} \mathrm{E}$ & Virtual GPS \\
Sofia & Sofia & $43^{\circ} 0^{\prime} 0^{\prime \prime} \mathrm{N}$ & $25^{\circ} 0^{\prime} 0^{\prime \prime} \mathrm{E}$ & Virtual GPS \\
El Arenosillo & Areno dps & $37^{\circ} 6^{\prime} 00^{\prime \prime} \mathrm{N}$ & $06^{\circ} 42^{\prime} 00^{\prime \prime} \mathrm{W}$ & Digisonde \\
Rome & Rome dps & $41^{\circ} 48^{\prime} 0^{\prime \prime} \mathrm{N}$ & $12^{\circ} 30^{\prime} 0^{\prime \prime} \mathrm{E}$ & Digisonde \\
\hline
\end{tabular}

station-satellite, and are the basis for 3D and 3D time-dependent imaging of the ionosphere.

In 2001 Spencer and Mitchell published results from a new type of ionospheric imaging based on GPS (Spencer and Mitchell, 2001), which overcame the limitations of the classic (LEO) ionospheric tomography. The GPS satellites are monitored by a network of dual-frequen- 
cy receivers, recording the phase and time delay of each signal. Such networks (for instance, IGS), spread all over the world, are open for data downloading providing a valuable source of information on the ionosphere in the form of raypath integrations of electron concentration. Nevertheless, these measurements are rather uneven in distribution and coverage. The new imaging technique, known as MIDAS (Multi-Instrument Data Analysis System), is unique in its approach to ionospheric imaging, because it performs a four-dimensional (i.e. 3D time-dependent) inversion (Mitchell and Spencer, 2003). It offers two key advantages: i) they are fully three-dimensional and ii) a novel time-dependent imaging technique allowed the ionosphere to be studied on time-scales of minutes. The University of Bath performed many studies as, more recently, imaging during extreme space-weather events known as storms has shown dramatic changes in the height of the ionosphere to occur over very short time-scales (Yin et al., 2004; Mitchell et al., 2005; De Franceschi et al., 2007). These sudden events are very important for radio communications because they cause radio signals to deviate from those paths predicted by ionospheric radiopropagation models. Storms also cause the absolute values of electron concentration to decrease during the negative storm phase, thus lowering the range of frequencies possible for $\mathrm{HF}$ communications. Real-time imaging of the ionosphere could assist in communications planning, reducing potential communications outages in storm times.

MIDAS is now under development for two aspects: first, its extension to polar regions (Spencer and Mitchell, 2007); second, real-time imaging. MIRTO, developed in cooperation with IFAC and INGV, represents the first step in this direction. The MIRTO project sets the aim of the realization of a prototype that produces images over Italy in near real-time making use of data acquired by the real-time ionospheric and geodetic instrumentation operated by INGV. In order to cover the western and eastern edges of the area defined by the system, a GPS receiver has been recently installed at Chania (Crete, Greece) and another one is being to be deployed in Spain (Huelva, El Aeronosillo Observatory) (fig. 1, table I). MIRTO technique uses ionosonde densi- ty profiles given in near real-time by some stations coordinated in the DIAS framework (Beleakhi et al., 2005). During the development of MIRTO when no data have been available at some stations, artificial data from IRI were used.

In this paper the MIRTO prototype is introduced and described underlining its potentialities in view of the realization of a useful tool for scientific aims and space weather applications. After a few hints on the theory of the inversion problem, the second section of the paper is mainly addressed to the description of the method used by MIRTO for imaging the ionosphere; the first results of the prototype and the next steps of the project are described and discussed in the third and last section.

\section{Method and development}

The total electron content is defined as the line integral of the electron concentration along a path from a satellite to a receiver. Dual frequency radio signals that propagate through the ionosphere are subject to a differential phase change due to the dispersive nature of the plasma. As a first order approximation the change in the differential phase shift is directly proportional to the change in TEC between the transmitter and receiver.

An outline of the theory of the inversion problem can be found in Mitchell and Spencer (2003) and references therein. Here we only recall the crucial steps of the inversion approach applied to GPS signals, which are: a) set up a three-dimensional grid of $j$ voxels (i.e. volume pixels), each bounded in latitude, longitude and altitude; b) compute the length of all elements of every $i$-th satellite-to-receiver ray-path through each intersected voxel. The unknown electron concentration $x$ is defined to be constant within each voxel. The problem may now be expressed as

$$
A \boldsymbol{x}=\boldsymbol{b}
$$

where $\boldsymbol{A}$ is an $i \times j$ matrix of the path lengths within each voxel and $\boldsymbol{b}$ are the $i$ observed TECs. This cannot be solved directly as the matrix $\boldsymbol{A}$ is rectangular, highly singular and incorporates no prior information as to the likely so- 

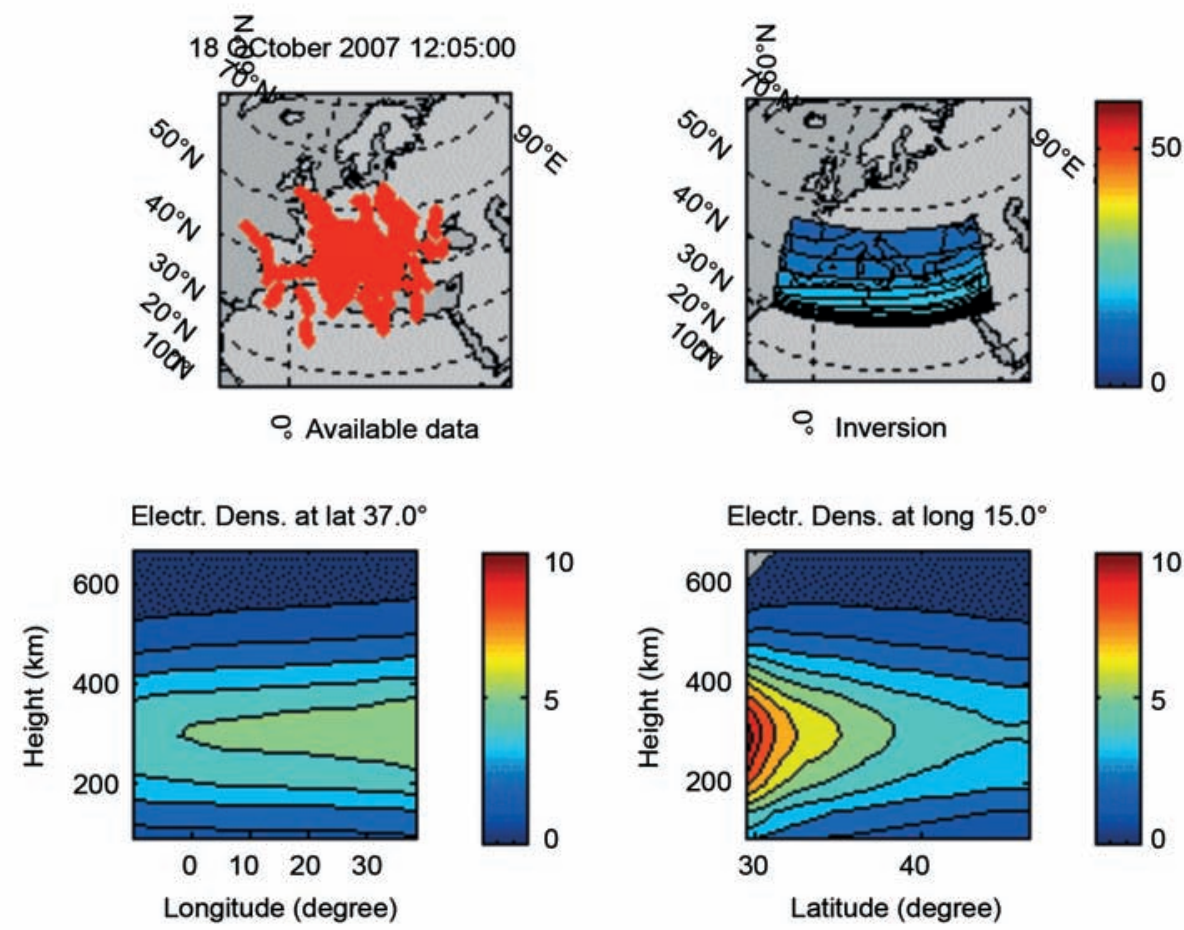

Fig. 2. Typical output of MIRTO. Clockwise: tracks of all the satellites in view from the MIRTO stations; TEC map (in TECu $=10^{16} \mathrm{~m}^{-2}$ ); latitudinal and longitudinal sections of the electron density (in $10^{11} \mathrm{~m}^{-3}$ ).

lution. To overcome this difficulty a mapping matrix, $\boldsymbol{X}$, is used to transform the problem to one for which the unknowns are $n$ coefficients of orthonormal basis functions, the combination of which will give the final image of electron concentration. Here the basis functions $(\boldsymbol{X})$ were generated using a spherical harmonic expansion to represent the horizontal variation and Empirical Orthonormal Functions (EOFs) for the radial variation in electron concentration (Mitchell and Spencer, 2003). For MIRTO, the radial dependence in EOFs is derived from density profiles provided by the ionosondes (Materassi and Mitchell, 2005). After these inversions, MIRTO produces density profiles images over Italy and Mediterranean area in close to real-time, i.e. with a latency of $15 \mathrm{~min}$. According to the different information needed by the applications, the system can provide TEC maps, TEC gradients, ionization sections, electron density profiles, peak density and height over the region of interest (fig. 2).

The first phase of the project was spent using the existing data to upgrade and test the real time version of MIDAS, to develop all the networking software for the GPS data, to integrate the system with other European existing real time GPS data (SOPAC) and ionosonde real time data and, finally, to produce and flow the images to the main station to be distributed.

The data sources of the system are: IGS (International GPS Service) for the orbital data, INGV national network RING (Rete Integrata Nazionale GPS) located in Italy for the L1 and L2 signals (fig. 1, table I), one GISTM (GPS Ionospheric Scintillation and TEC Monitor, Van Dierendonck et al., 1993; De Franceschi et al., 2006) receiver managed by INGV and located in Chania (Greece) for TEC data and the DPS-4 digisonde in Rome and $\mathrm{El} \mathrm{Aeronosillo} \mathrm{for} \mathrm{the}$ 
electron density profiles (SAO format; Reinisch, 1998). Moreover the system makes use of GPS artificial data (IRI, International Reference Ionosphere; Bilitza, 2001) from locations of possible future receivers and of artificial Chapman profiles (see e.g., Rishbeth and Garriott, 1969) to contribute to EOF's construction. The locations of the MIRTO stations are listed in table I.

The system works according to the following procedure: it reads the orbit elements from the data centres, the GPS data from MIRTO and RING stations and the ionosonde data from the Rome DPS-4; after the creation of artificial data from IRI for the virtual stations, it creates input matrices and then builds the EOF's using ionosonde data and model. Finally, the system inverts the data producing plots and output files. Every 15 min (at 5, 20, 35 and 50 min of each hour, according to the ionosonde sampling) MIRTO refreshes the input structures according to the incoming data (orbits, GPS and ionosonde data), inverts the data and produces the new outputs.

A typical MIRTO output is shown in fig. 2: on the top left are visualized the tracks of all satellites in view from the stations listed in table I; the right hand (top) map reports the TEC (in TECu) over the area of interest; the other two plots describe the longitudinal and latitudinal sections of the electron density in the same area.

The MIRTO project is now at the end of its second phase, essentially a test phase to assess the reliability of the data flow, the combination of the data into the MIDAS algorithm and the success in streaming of the ionospheric images to the user-interface. During this phase we also deployed a GISTM receiver in Chania (Crete, Greece) to cover the eastern edge of the area of interest. For the coverage of the western border, we are going to install another GISTM receiver in Spain (El Aeronosillo Observatory, Huelva).

\section{Next steps}

The third and last phase of the realization of the MIRTO prototype will be dedicated to the assessment of images for regions of data sparse, such as, for instance, North Africa, the assessment of the ionospheric imaging under perturbed conditions typical, for instance, of magnetic storms and the assessment of the database system. This period will also explore the possible acquisition of supplementary receivers where necessary.

The final aim of MIRTO is to realize a system able to produce monitoring of the ionosphere over the Mediterranean Sea in true realtime. To achieve this goal the imaging technique used by MIRTO is going to be implemented with forecasting tools. At that time the system will be tested to obtain information on the reliability of the MIRTO density images with respect to the real ionospheric scenario. The upgrading of the prototype will make MIRTO a real scientific tool of interest for scientific purposes and for space weather applications.

A continuous monitoring of the ionosphere may be of great use even at the mid-latitudes, monitored by MIRTO, where important «anomalous» phenomena are not locally triggered, but however do happen. Indeed, mid-latitudes can be affected by geomagnetic and ionospheric phenomena both because of perturbations coming from the North (e.g., Solar Flares, CMEs), and because of disturbances coming from the equatorial regions, due to the sudden variations in the magnetic and electric fields of the Earth. All these causes influence the electromagnetic wave propagation, affecting significantly communications and positioning.

\section{Acknowledgements}

This work was supported by the project MIUR RBAP04EF3A.

The authors thank the INGV national GPS network RING, the Laboratory of Geophysics \& Seismology of the Technological Educational Institute of Crete and the COST296 Action.

\section{REFERENCES}

Austen, J.R., S.J. Franke and C.H. LiU (1988): Ionospheric imaging using computerised tomography, Radio Sci., 23, 299-307.

Belehaki, A., Lu. Cander, B. Zolesi, J. Bremer, C. Juren, I. Stanislawska, D. Dialetis and M. Hatzopoulos (2005): DIAS Project: the establishment of a European digital upper atmosphere server, J. Atmos. Solar-Terr. Phys., 67, 1092-1099. 
BiLITZA, D. (2001): International reference ionosphere 2000, Radio Sci., 36, 261-275.

DAVIES, K. (1990): Ionospheric Radio (Peregrinus Ltd., London, U.K.), pp. 580.

De Franceschi, G., L. Alfonsi and V. Romano (2006): ISACCO: an Italian project to monitor the high latitudes ionosphere by means of GPS receivers, GPS Solut., 10 (4), 263-267.

De Franceschi, G., L. Alfonsi, V. Romano, M. Aquino, A. Dodson, C.N. Mitchell and A.W. Wernik (2007): Dynamics of high latitude patches and associated small scale irregularities, J. Atmos. Solar-Terr. Phys., doi: 10.1016/j.jastp.2007.05.018.

HounsFIELD, G.N. (1972): A method of and apparatus for examination of a body by radiation such as $X$-ray or gamma radiation, Patent Specification 1283915, The Patent Office.

Materassi, M. and C.N. Mitchell (2005): A simulation study into constructing of the sample space for ionospheric imaging, J. Atmos. Solar-Terr. Phys., 67/12, $1085-$ 1091.

Mitchell, C.N. and P.S.J. Spencer (2003): A three-dimensional time-dependent algorithm for ionospheric imaging using GPS, Ann. Geophysics, 46 (4), 687-696.

Mitchell, C.N., L. Alfonsi, G. De Franceschi, M. Lester, V. Romano and A.W. WERniK (2005): GPS TEC and scintillation measurements from the polar ionosphere during the October 2003 storm, Geophys. Res. Lett., 32, L12S03, doi: 10.1029/2004GL021644.

REINISCH, B.W. (1998): SAO (Standard ADEP Output) format for ionogram scaled data archiving, INAG Bull., 62, 47-58.

Rishbeth, H. and O.K. GARRIOTT (1969): Introduction to Ionospheric Physics (Academic Press, New York).

SPENCER, P.S.J. and C.N. Mitchell (2001): Multi-instrument inversion technique for ionospheric imaging, in Proceedings International Beacon Satellite Symposium, edited by P. DOHERTY, Boston, MA.

SPENCER, P.S.J. and C.N. MitChELl (2007): Imaging of fast moving electron-density structures in the polar cap, Ann. Geophysics, 50 (3), 427-434 (this volume).

VAn DieRendoncK, A.J., J. KLOBUChaR and Q. Hua (1993): Ionospheric scintillation monitoring using commercial single frequency C/A code receivers, in ION GPS-93 Proceedings: Sixth International Technical Meeting of the Satellite Division of the Institute of Navigation, Inst. of Navig., Salt Lake City, Utah, 1333-1342.

Yin, P., C.N. Mitchell, P.S.J. Spencer and J.C. Foster (2004): Ionospheric electron concentration imaging using GPS over the U.S.A. during the storm of July 2000, Geophys. Res. Lett., 31 (12), L12806.

(received September 10, 2007; accepted October 19, 2007) 


\section{ANNALS OF GEOPHYSICS}

\begin{tabular}{|c|c|c|}
\hline & Individual & Organizations \\
\hline Annual subscription rates 2007 for Italy & $€ 26$ & $€ 62$ \\
\hline Annual subscription rates 2007 for other countries & $€ 43$ & $€ 108$ \\
\hline
\end{tabular}

Address

Tel. or fax No.

Postal code

Town

Country

Payment to EDITRICE COMPOSITORI by

$\square$ Italian postal account No. 19136407

(only for Italian subscribers)

$\square$ enclosed cheque

$\square$ Credit Card

Card No.

Address given to Credit Institute

Expiry date

Date of birth

Date Signature
CartaSì
$\square$ Visa
EuroCard
Master Card

Please mail or send by fax to:

\section{EDITRICE COMPOSITORI}

Via Stalingrado 97/2 ${ }^{\circ} 40128$ BOLOGNA (Italy)

Tel. (39) 051-3540111 - Fax (39) 051-327877

e-mail: 1865@compositori.it http://www.compositori.it 

C 2007 by Istituto Nazionale di Geofisica e Vulcanologia Proprietà letteraria riservata

Direttore responsabile: Enzo Boschi
(1) Questo periodico è iscritto U1 all'Unione Stampa Periodica Italiana

Autorizzazione del Tribunale di Bologna n. 6125 del 21.7.1992

Stampato da Compositori Ind. Grafiche, Bologna nell'anno 2007 
